\title{
AN ATTEMPT TO DEVELOP AN ENVIRONMENTAL INFORMATION SYSTEM OF ECOLOGICAL INFRASTRUCTURE FOR EVALUATING FUNCTIONS OF ECOSYSTEM-BASED SOLUTIONS FOR DISASTER RISK REDUCTION (ECO-DRR)
}

\author{
T. Doko ${ }^{\text {a, b }}$, W. Chen ${ }^{\text {a, b }}$, K. Sasaki ${ }^{\text {a, c }}$, T. Furutani ${ }^{\text {a }}$

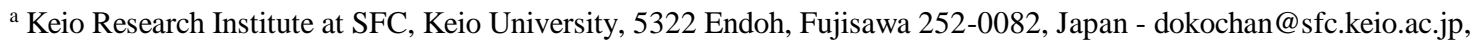 \\ maunz@sfc.keio.ac.jp \\ b Nature \& Science Consulting Co., Ltd., Room 302, 3F, Chuo-dairoku-kannai Bld., 1-2-1 Furocho, Naka-ku, Yokohama 231-0032, \\ Japan - doko@ nature-science-consulting.co.jp, chen@ nature-science-consulting.co.jp \\ ${ }^{c}$ Department of Animal Ecology \& Systematics, Animal Ecology, Justus Liebig University \\ Heinrich-Buff Ring 26-32, 35392 Giessen, Germany - pflanzen1987@ gmail.com
}

Commission VIII, WG VIII/1

KEY WORDS: Ecological infrastructure, Eco-DRR, Environmental Information System, Ecological disaster reduction, Web-GIS

\begin{abstract}
:
"Ecological Infrastructure (EI)" are defined as naturally functioning ecosystems that deliver valuable services to people, such as healthy mountain catchments, rivers, wetlands, coastal dunes, and nodes and corridors of natural habitat, which together form a network of interconnected structural elements in the landscape. On the other hand, natural disaster occur at the locations where habitat was reduced due to the changes of land use, in which the land was converted to the settlements and agricultural cropland. Hence, habitat loss and natural disaster are linked closely. Ecological infrastructure is the nature-based equivalent of built or hard infrastructure, and is as important for providing services and underpinning socio-economic development. Hence, ecological infrastructure is expected to contribute to functioning as ecological disaster reduction, which is termed Ecosystem-based Solutions for Disaster Risk Reduction (Eco-DRR). Although ecological infrastructure already exists in the landscape, it might be degraded, needs to be maintained and managed, and in some cases restored. Maintenance and restoration of ecological infrastructure is important for security of human lives. Therefore, analytical tool and effective visualization tool in spatially explicit way for the past natural disaster and future prediction of natural disaster in relation to ecological infrastructure is considered helpful. Hence, Web-GIS based Ecological Infrastructure Environmental Information System (EI-EIS) has been developed. This paper aims to describe the procedure of development and future application of EI-EIS. The purpose of the EI-EIS is to evaluate functions of Eco-DRR. In order to analyse disaster data, collection of past disaster information, and disaster-prone area is effective. First, a number of digital maps and analogue maps in Japan and Europe were collected. In total, 18,572 maps over 100 years were collected. The Japanese data includes Future-Pop Data Series (1,736 maps), JMC dataset 50m grid (elevation) (13,071 maps), Old Edition Maps: Topographic Map (325 maps), Digital Base Map at a scale of 2500 for reconstruction planning (808 maps), Detailed Digital Land Use Information for Metropolitan Area (10 $\mathrm{m}$ land use) (2,436 maps), and Digital Information by GSI (national large scale map) (71 maps). Old Edition Maps: Topographic Map were analogue maps, and were scanned and georeferenced. These geographical area covered 1) Tohoku area, 2) Five Lakes of Mikata area (Fukui), 3) Ooshima Island (Tokyo), 4) Hiroshima area (Hiroshima), 5) Okushiri Island (Hokkaido), and 6) Toyooka City area (Hyogo). The European data includes topographic map in Germany (8 maps), old topographic map in Germany (31 maps), ancient map in Germany (23 maps), topographic map in Austria (9 maps), old topographic map in Austria (17 maps), and ancient map in Austria (37 maps). Second, focusing on Five Lakes of Mikata area as an example, these maps were integrated into the ArcGIS Online ${ }^{\circledR}$ (ESRI). These data can be overlaid, and time-series data can be visualized by a time slider function of ArcGIS Online.
\end{abstract}

\section{INTRODUCTION}

"Ecological Infrastructure (EI)" are defined as naturally functioning ecosystems that deliver valuable services to people, such as healthy mountain catchments, rivers, wetlands, coastal dunes, and nodes and corridors of natural habitat, which together form a network of interconnected structural elements in the landscape. On the other hand, natural disaster occur at the locations where habitat was reduced due to the changes of land use, in which the land was converted to the settlements and agricultural cropland. Hence, habitat loss and natural disaster are linked closely. Ecological infrastructure is the nature-based equivalent of built or hard infrastructure, and is as important for providing services and underpinning socio-economic development.

Hence, ecological infrastructure is expected to contribute to functioning as ecological disaster reduction, which is termed Ecosystem-based Solutions for Disaster Risk Reduction (EcoDRR). Eco-DRR is the sustainable management, conservation and restoration of ecosystems to reduce disaster risk, with the aim of achieving sustainable and resilient development (Renaud, Sudmeier-Rieux, \& Estrella, 2013). After decades of neglect, the importance of protecting and improving ecosystems for reducing

\footnotetext{
* Corresponding author
} 
disaster risk started to receive attention in the recent years (Gupta \& Nair, 2012).

Although ecological infrastructure already exists in the landscape, it might be degraded, needs to be maintained and managed, and in some cases restored. Maintenance and restoration of ecological infrastructure is important for security of human lives. Therefore, analytical tool and effective visualization tool in spatially explicit way for the past natural disaster and future prediction of natural disaster in relation to ecological infrastructure is considered helpful. Web-GIS based Ecological Infrastructure Environmental Information System (EI-EIS) has been developed. This paper aims to describe the procedure of development and future application of EI-EIS.

\section{METHODS}

The purpose of the EI-EIS is to evaluate functions of Eco-DRR. In order to analyse disaster data, collection of past disaster information, and disaster-prone area is effective.

First, a number of digital maps and analogue maps in Japan and Europe were collected. Old Edition Maps: Topographic Map were analogue maps, and were scanned and georeferenced. These geographical area covered 1) Tohoku area, 2) Five Lakes of Mikata area (Fukui), 3) Ooshima Island (Tokyo), 4) Hiroshima area (Hiroshima), 5) Okushiri Island (Hokkaido), and 6) Toyooka City area (Hyogo). The European data includes topographic map, old topographic map, and ancient map, in Germany and in Austria, respectively. Most of these maps are analogue maps too, and were scanned and georeferenced.

Second, focusing on Five Lakes of Mikata area in Fukui Prefecture of Japan and several areas of Austria and Germany as demonstration, these maps were integrated into the ArcGIS Online $^{\circledR}$ (ESRI). These data were able to be overlaid, and timeseries data were able to be visualized by a time slider function of ArcGIS Online.

\section{RESULTS}

\subsection{Dataset}

The geographic data which covers Japan contained 1) Future-Pop Data Series (1,736 maps), 2) JMC dataset $50 \mathrm{~m}$ grid (elevation) (13,071 maps), 3) Old Edition Maps: Topographic Map (325 maps), 4) Digital Base Map at a scale of 2500 for reconstruction planning (808 maps), 5) Detailed Digital Land Use Information for Metropolitan Area (10 m land use) (2,436 maps), and 6) Digital Information by GSI (national large scale map) (71 maps). The total number of maps covering Japan was 18,447.

On the other hand, the geographic data which covers Europe contained topographic map in Germany (8 maps), old topographic map in Germany (31 maps), ancient map in Germany (23 maps), topographic map in Austria (9 maps), old topographic map in Austria (17 maps), and ancient map in Austria (37 maps). The total number of maps covering Europe was 125 .

In total, 18,572 maps covering geographic area of Japan and Europe were collected (Table 1).

\begin{tabular}{|c|c|c|}
\hline Data name & $\begin{array}{l}\text { No. of } \\
\text { maps }\end{array}$ & Data size \\
\hline Future-Pop Data Series (Japan) & 1,736 & $4.92 \mathrm{~GB}$ \\
\hline $\begin{array}{l}\text { JMC dataset 50m grid (elevation) } \\
\text { (Japan) }\end{array}$ & 13,071 & $1.56 \mathrm{~GB}$ \\
\hline $\begin{array}{l}\text { Old Edition Maps: Topographic Map } \\
\text { (Japan) }\end{array}$ & 325 & $144 \mathrm{MB}$ \\
\hline $\begin{array}{l}\text { Digital Base Map at a scale of } 2500 \text { for } \\
\text { reconstruction planning (Japan) }\end{array}$ & 808 & $812 \mathrm{MB}$ \\
\hline $\begin{array}{l}\text { Detailed Digital Land Use Information } \\
\text { for Metropolitan Area ( } 10 \mathrm{~m} \text { land use) } \\
\text { (Japan) }\end{array}$ & 2,436 & $1.20 \mathrm{~GB}$ \\
\hline $\begin{array}{l}\text { Digital Information by GSI (national } \\
\text { large scale map) (Japan) }\end{array}$ & 71 & $3.39 \mathrm{~GB}$ \\
\hline Topographic map (Germany) & 8 & $4.18 \mathrm{~GB}$ \\
\hline Old topographic map (Germany) & 31 & $3.10 \mathrm{~GB}$ \\
\hline Ancient map (Germany) & 23 & $5.88 \mathrm{~GB}$ \\
\hline Topographic map (Austria) & 9 & $3.04 \mathrm{~GB}$ \\
\hline Old topographic map (Austria) & 17 & $538 \mathrm{MB}$ \\
\hline Ancient map (Austria) & 37 & $748 \mathrm{MB}$ \\
\hline Total & 18,572 & $29.61 \mathrm{~GB}$ \\
\hline
\end{tabular}

Table 1. Summary of dataset

\subsection{Details of dataset}

3.2.1 Future-Pop Data Series (Japan): The Future-Pop Data series (Microbase Co. Ltd., 2016) provides population census prediction for $500 \mathrm{~m}$ mesh of whole Japan. The coverage of period is 2010 to 2040. The example data was given in Fig. 1. A total of 1,736 maps were collected in this study.

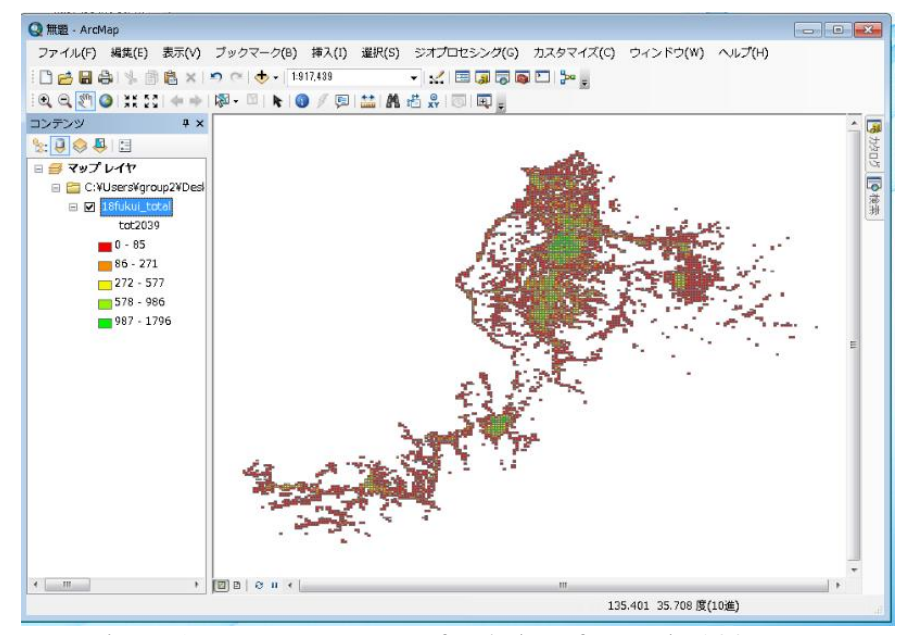

Figure 1. Future-Pop Data of Fukui Prefecture in 2039 
3.2.2 JMC dataset 50m grid (elevation) (Japan): The JMC dataset $50 \mathrm{~m}$ grid (elevation) is Digital Elevation Model data and was purchased from Japan Map Center Foundation (Japan Map Center Foundation, 2016d). This data is equivalent to "Digital Map 50m Grid (Elevation)”, which was published by Geospatial Information Authority of Japan of Ministry of Land, Infrastructure, Transport and Tourism, based on "Fundamental Geospatial Data (Digital Elevation Model) $10 \mathrm{~m}$ mesh" provided by Geospatial Information Authority of Japan of Ministry of Land, Infrastructure, Transport and Tourism.

First, standard area mesh (secondary mesh) was divided into 200 equal parts in the longitude direction and the latitude direction respectively.

Seondly, a central altitude of each obtained division (on 1/20 subdivision mesh, about $2 \mathrm{~mm}$ x about $2 \mathrm{~mm}$ on Topographical Map of 1:25,000) was recorded. The interval of obtained division was at 1.5 seconds for the latitude (north-south) direction, and at 2.25 seconds for longitude direction, which was about $50 \mathrm{~m}$ x $50 \mathrm{~m}$ for actual distance. The data format were in both MEM format and GeoTiff format (Fig. 2 for example). A total of 13,071 maps were collected in this study.

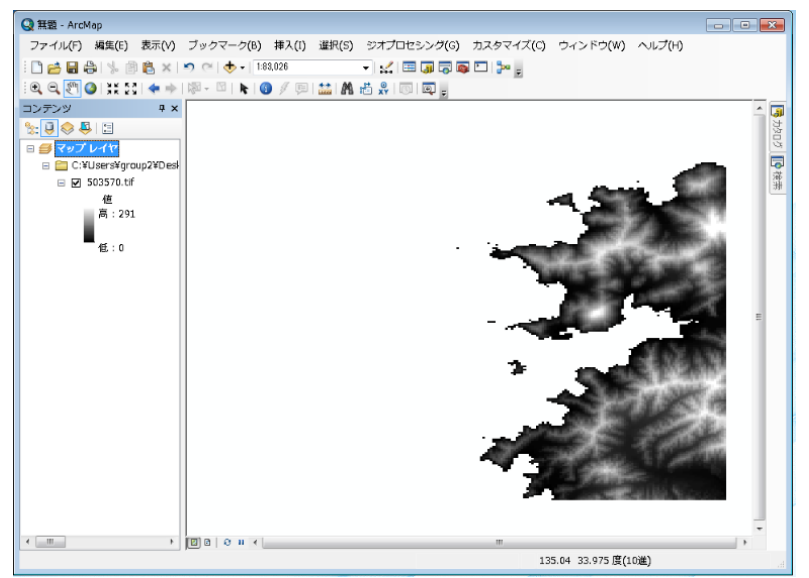

Figure 2. JMC 50m mesh DEM data

3.2.3 Old Edition Map: Topographic Map (Japan): Old Edition Map was published by Geospatial Information Authority of Japan of Ministry of Land, Infrastructure, Transport and Tourism. Topographic Map is one of series of Old Edition Map (Geospatial Information Authority of Japan, 2016) (Fig. 3 as an example).

In Geospatial Information Authority of Japan of Ministry of Land, Infrastructure, Transport and Tourism, any map which is not the latest map published is defined as "Old Edition Map". Old Edition Maps are available as photocopies in hardcopies. Thus, these hardcopies were scanned and georeferenced. A total of 325 maps were collected in this study.

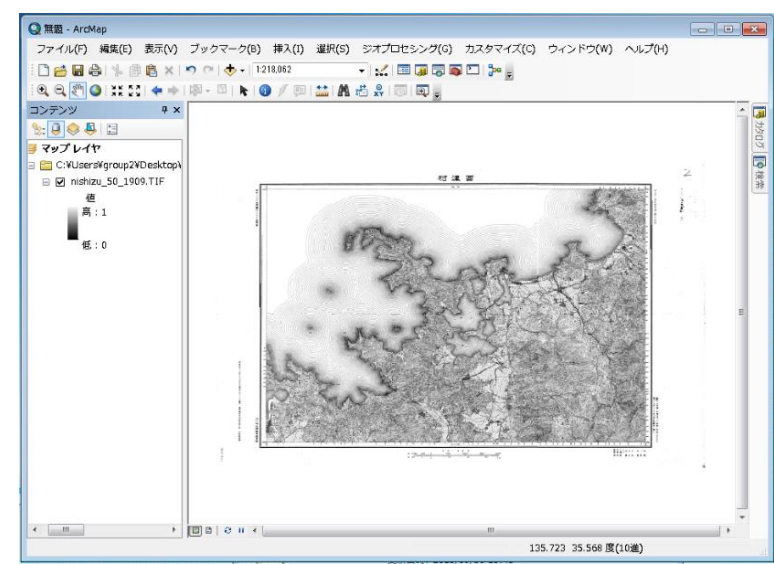

Figure 3. Old Edition Map: Topographic Map (Nishizu, $1: 50,000,1909)$

3.2.4 Digital Base Map at a scale of 2500 for reconstruction planning (Japan): "Digital Base Map at a scale of 2500 for reconstruction planning (DM data online)"(Japan Map Center Foundation, 2016b) is the large-scale numerical topographic map product which aims to promote reconstruction planning and to implement reconstruction procedures efficiently after Eastern Japan Great Disaster. This data includes administrative boundaries, transportation facilities, buildings, land use, and topography (Fig. 4 as an example). A total of 808 maps were collected in this study.

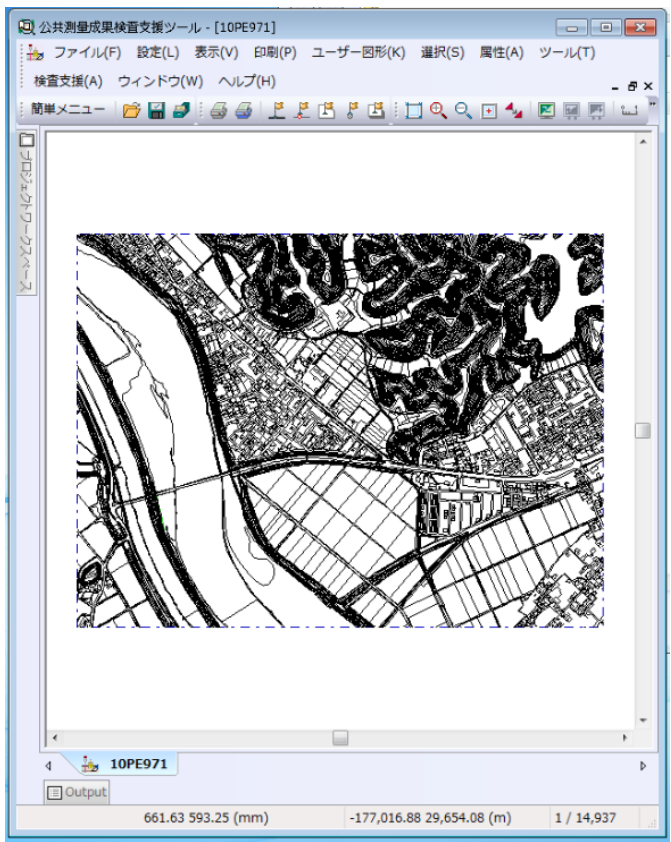

Figure 4. Digital Base Map at a scale of 2500 for reconstruction planning 
3.2.5 Detailed Digital Land Use Information for Metropolitan Area (10 m land use) (Japan): "Detailed Digital Land Use Information for Metropolitan Area (10 m land use)"(Japan Map Center Foundation, 2016a) is the map product which is the achievement of residential land use trend survey between 1981 and 1997 (Fig. 5 as an example). The residential land use trend survey was held every five years for three major metropolitan areas (Capital Area, Chubu Area, Kinki Area). This data is composed by land use at $10 \mathrm{~m}$ mesh and administrative boundaries at $10 \mathrm{~m}$ mesh. The data was created based on aerial photograph interpretation for 15 types of land use. One file is composed by $3 \mathrm{~km}$ by $4 \mathrm{~km}$. A total of 2,436 maps were collected in this study.

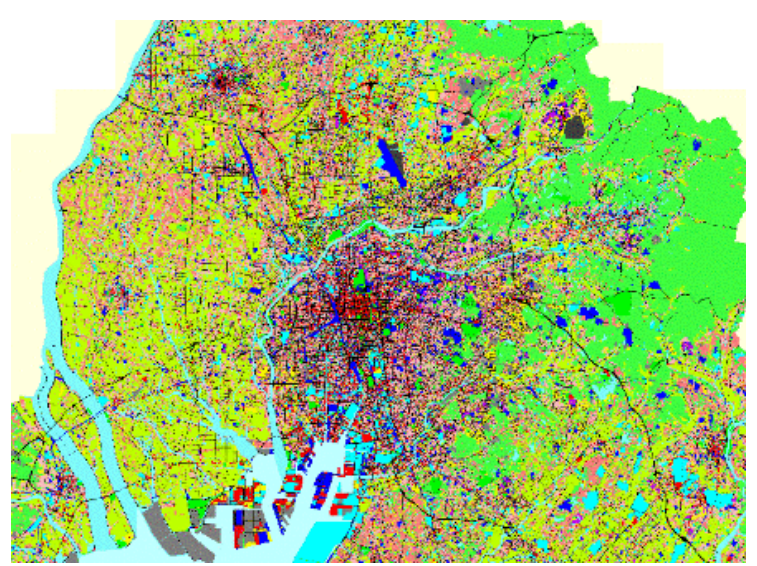

Figure 5. Detailed Digital Land Use Information for Metropolitan Area (10 m land use) (Chubu Area, 1977)

3.2.6 Digital Information by GSI (national large scale map) (Japan): "Digital Information by GSI (national large scale map)"(Japan Map Center Foundation, 2016c) is the map product which integrates Fundamental Geospatial Data, Digital Information by GSI (Geospatial Data Infrastructure, administrative boundaries, coastlines, location name, public facilities), and Digital Map (Elevation: $5 \mathrm{~m}, 10 \mathrm{~m}, 50 \mathrm{~m}$ mesh) (Fig. 6 as an example). A total of 71 maps were collected in this study.

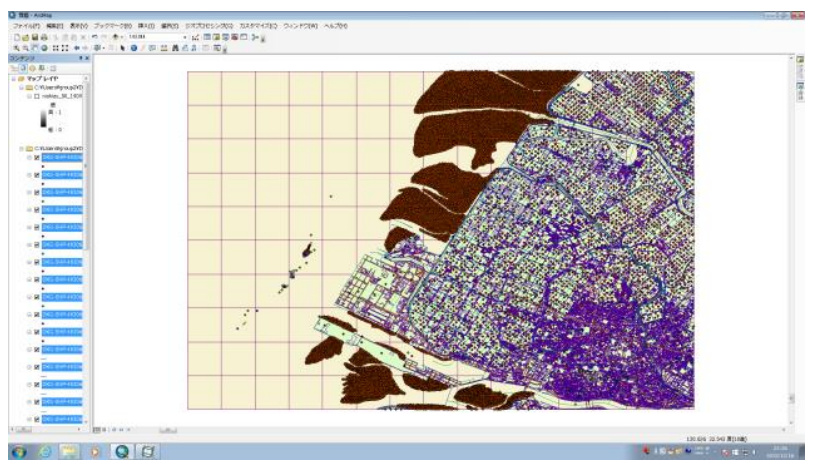

Figure 6. Digital Information by GSI (national large scale map)
3.2.7 Topographic map (Germany): Hessische Verwaltung für Bodenmanagement und Geoinformation (HVBG) publishes topographic maps at three scales: 25,000, 50,000, and 100,000. The collected map was topographic maps of 1: 25,000 (Hessische Verwaltung für Bodenmanagement und Geoinformation (HVBG), 2016b). One scene covers $12 \mathrm{~km}$ by $11 \mathrm{~km}$. HVBG handles 164 topographic maps (Fig. 7 as an example). These hardcopies were scanned and georeferenced. A total of 8 maps were collected in this study.

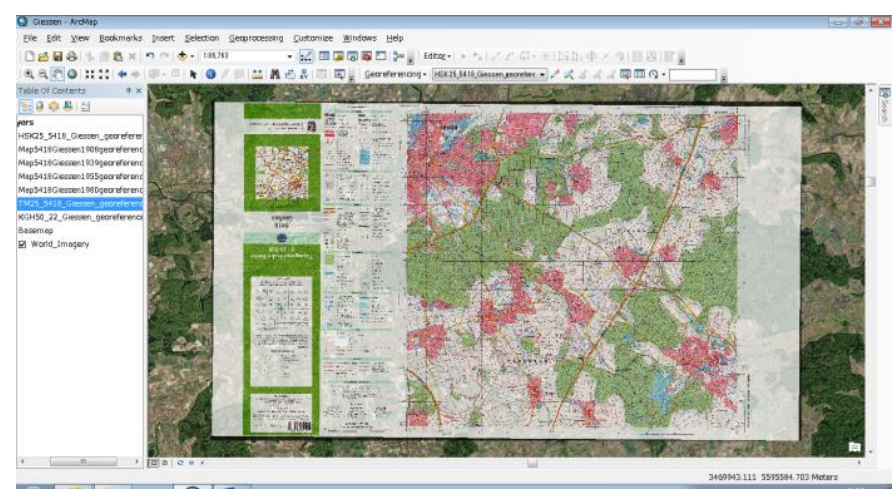

Figure 7. Topographic map, Giessen pronunciation in Germany $(1: 25,000)$

3.2.8 Old topographic map (Germany): "Old topographic map" is defined as out-of-print maps, which were published in past (Fig. 8 as an example). The Land Hessen has started to consolidate topographic maps at the scale of 1:25,000 since the beginning of the twenty century. Since then, the Land Hessen modify and update these maps. These hardcopies were scanned and georeferenced. A total of 31 maps were collected in this study.

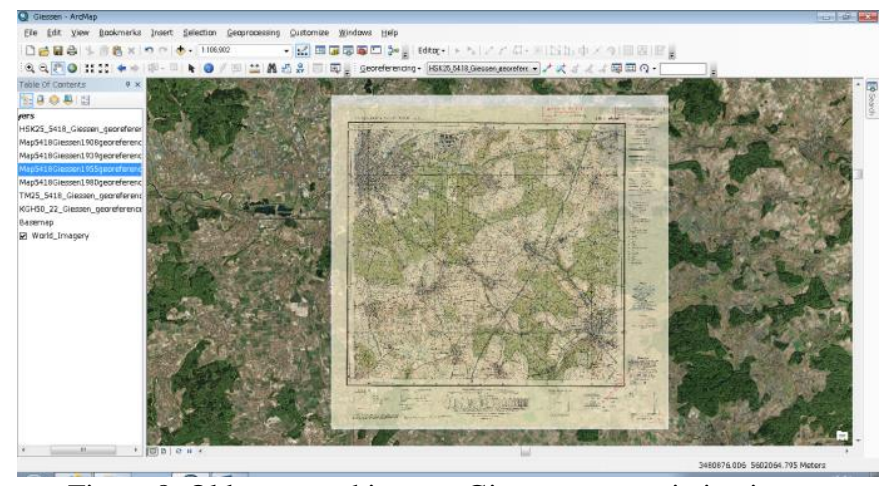

Figure 8. Old topographic map, Giessen pronunciation in Germany $(1: 25,000)$

3.2.9 Ancient map (Germany): The Ancient map means the past maps except topographic maps (Hessische Verwaltung für Bodenmanagement und Geoinformation (HVBG), 2016a). The Land Hessen handles maps in the eighteenth century and nineteenth century (Fig. 9 as an example). These hardcopies were scanned and georeferenced. A total of 23 maps were collected in this study. 


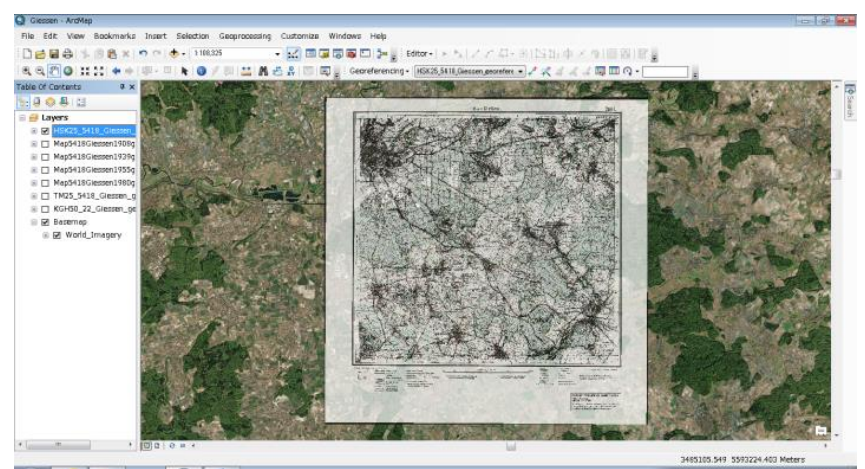

Figure 9. Ancient map, Giessen pronunciation in Germany $(1: 25,000)$

3.2.10 Topographic map (Austria): Federal Office of Metrology and Surveying: BEV publishes four types of topographic maps, which are scaled at 1: 25,000, 1:50,000, 1:250,000, and 1:500,000. The collected maps were topographic maps at 1:50,000 (Federal Office of Metrology and Surveying: BEV, 2016b). One scene covers approximately $560 \mathrm{~km}^{2}$ by topographic maps at 1:50,000. In Austria, there were 191 topographic maps at 1:50,000 (Fig. 10 as an example). These hardcopies were scanned and georeferenced. A total of 9 maps were collected in this study.

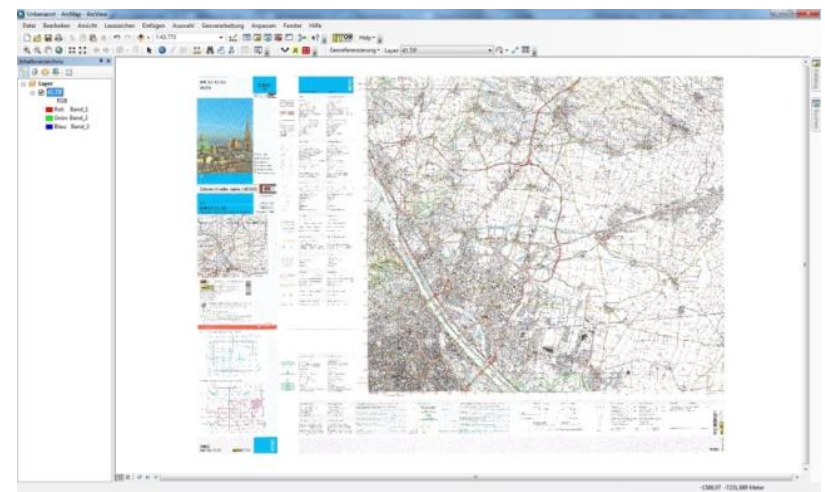

Figure 10. Topographic map, Vienna, Austria (1:50,000)

3.2.11 Old topographic map (Austria): "Old topographic map" is defined as out-of-print maps, which were published in past (Federal Office of Metrology and Surveying: BEV, 2016a). The part of Austria consolidated topographic maps at the scale of 1:25,000 between 1923 and 1959. After that, Austria unified the scale to $1: 50,000$ and promoted consolidation at national basis (Fig. 11 as an example). These hardcopies were scanned and georeferenced. A total of 17 maps were collected in this study.

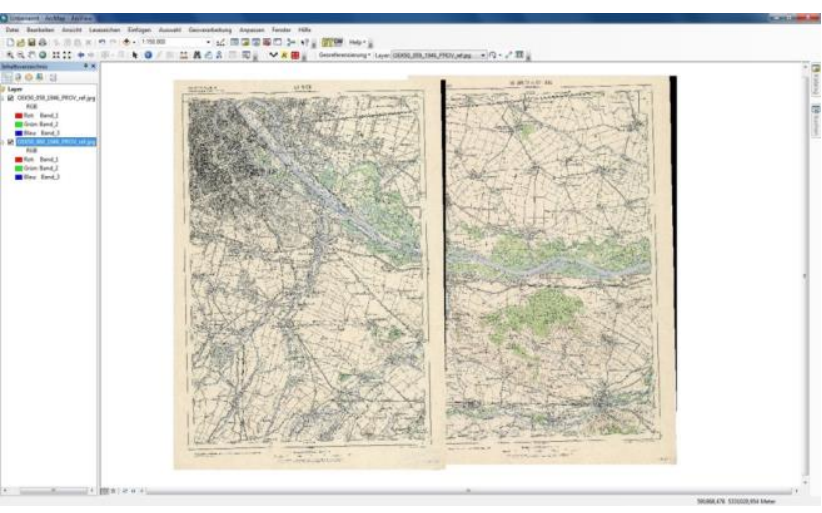

Figure 11. Old topographic map, Vienna, Austria (1:50,000)

3.2.12 Ancient map (Austria): The Ancient map means the past maps except topographic maps. In this study, maps from the third national wide survey (1869-1887) and maps at the scale of 1:75,000 (1872-1944) were collected (Fig. 12 as an example) (Federal Office of Metrology and Surveying: BEV, 2016a). These hardcopies were scanned and georeferenced. A total of 37 maps were collected in this study.

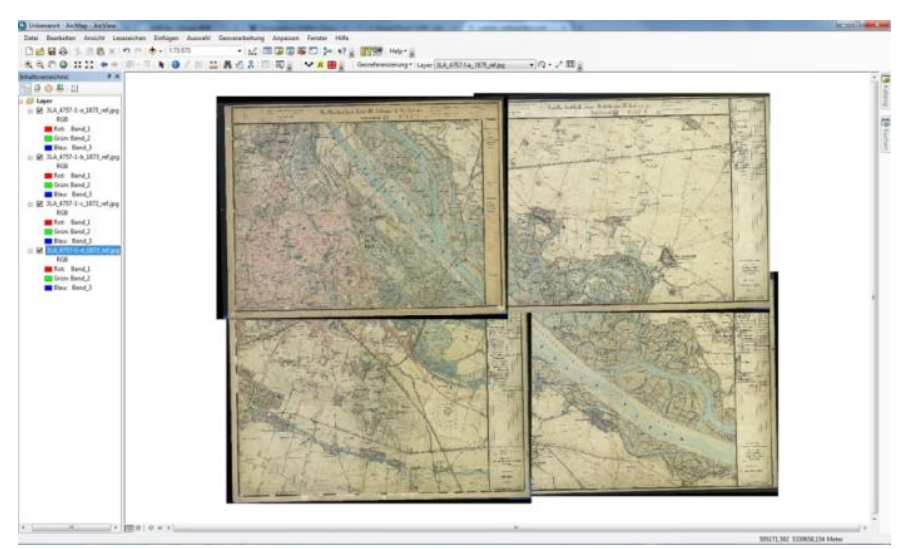

Figure 12. Ancient map, Vienna, Austria $(1: 75,000)$

\subsection{Development of ArcGIS Online}

Focusing on Five Lakes of Mikata area as an example, these maps were integrated into the ArcGIS Online ${ }^{\circledR}$ (ESRI). These data can be overlaid, and time-series data can be visualized by a time slider function of ArcGIS Online (Fig. 13 to Fig. 22).

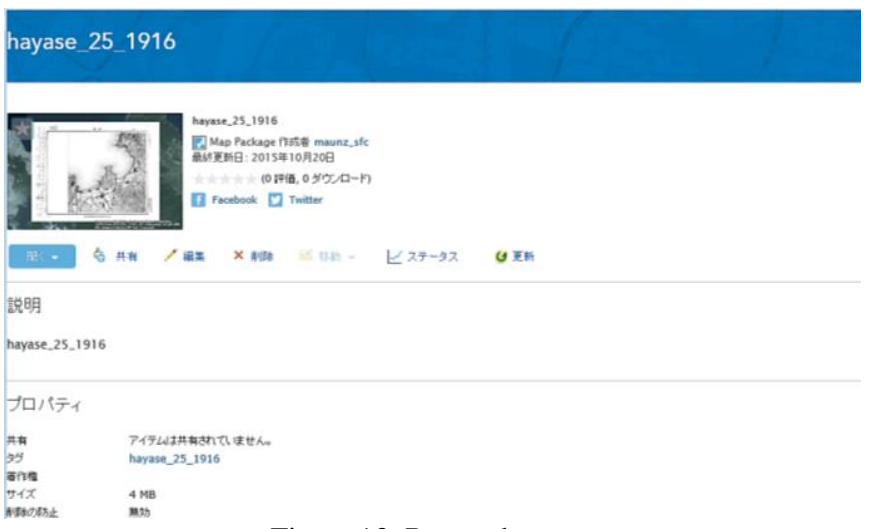

Figure 13. Raster data 


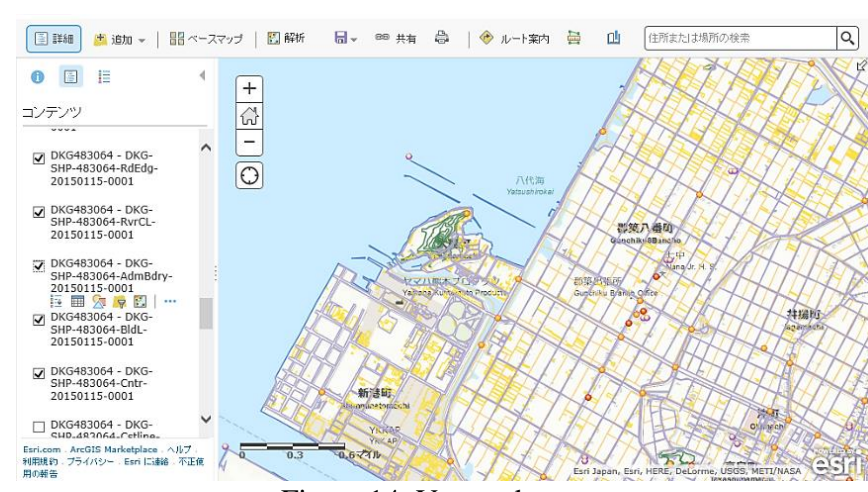

Figure 14. Vector data

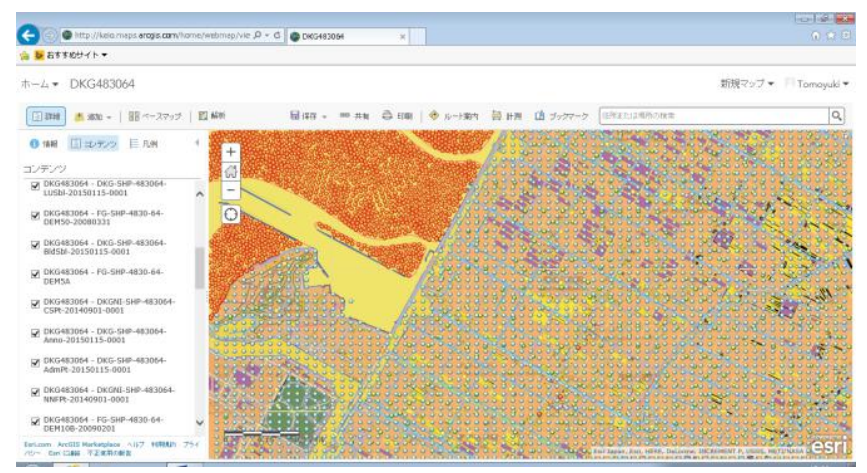

Figure 15. Digital Information by GSI (national large scale map) (Japan)

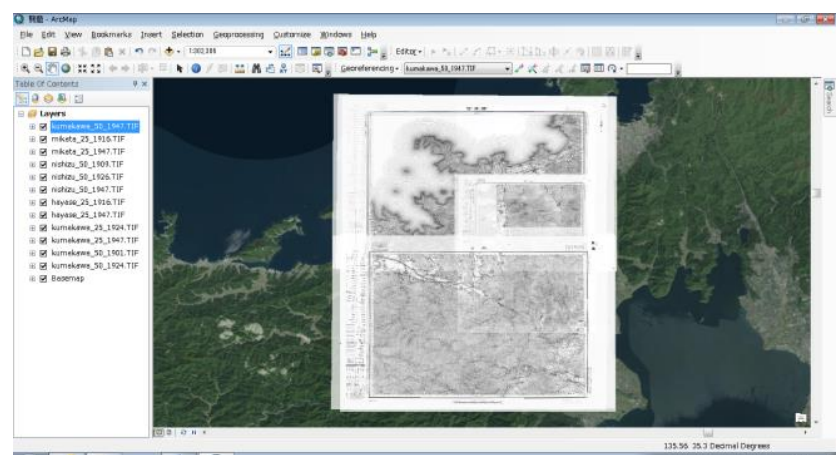

Figure 16. Overlay of Old Edition Map: Topographic Map (Japan) in ArcGIS Online

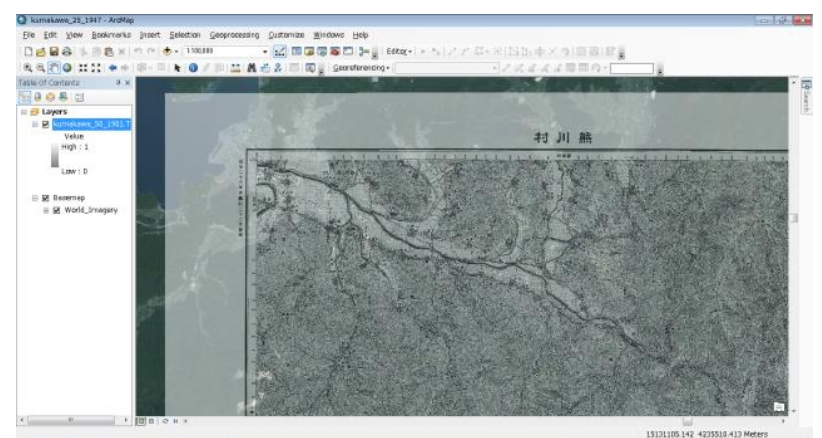

Figure 17. Overlay of Old Edition Map: Topographic Map (Japan) in ArcGIS Online with $30 \%$ transparancy

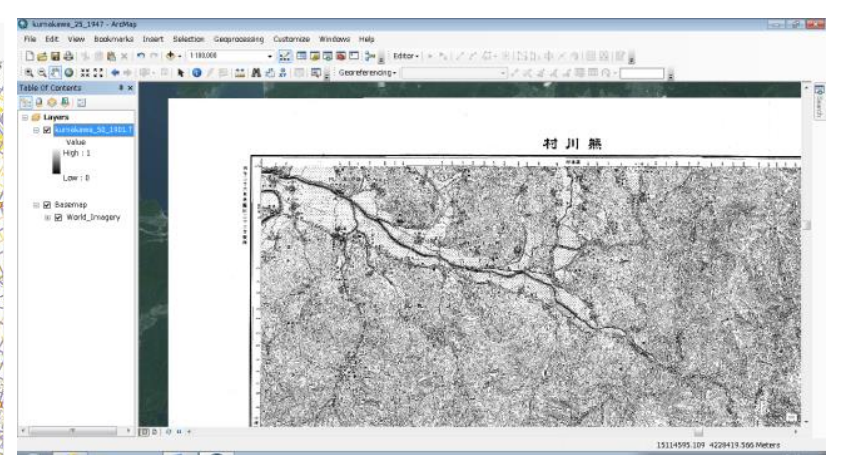

Figure 18. Overlay of Old Edition Map: Topographic Map (Japan) in ArcGIS Online with 0\% transparancy

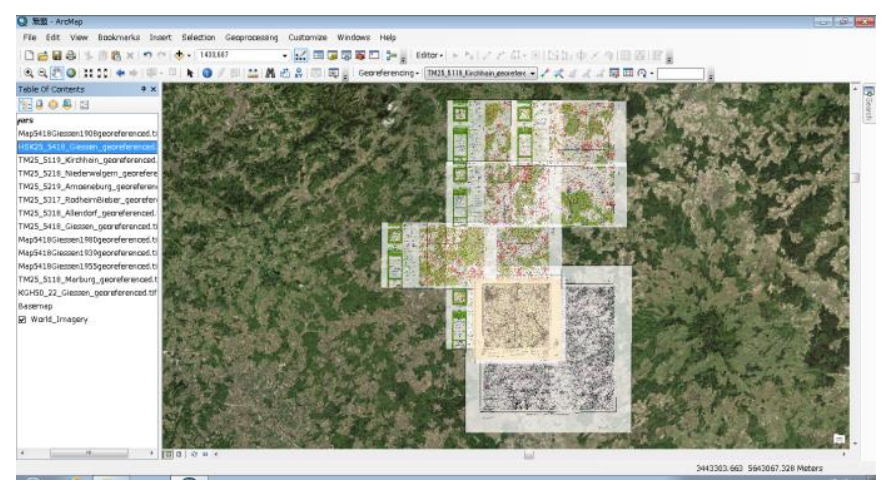

Figure 19. Overlay of maps of Germany and Austria

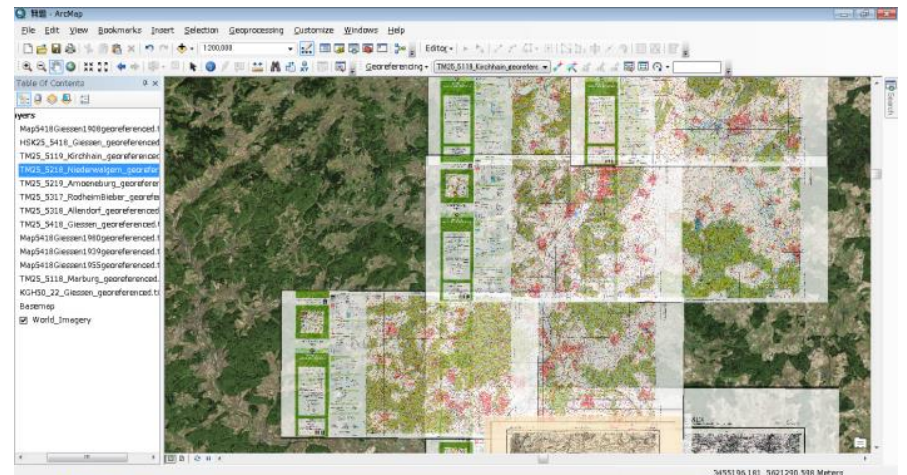

Figure 20. Zoomed-in Overlay of maps of Germany and Austria

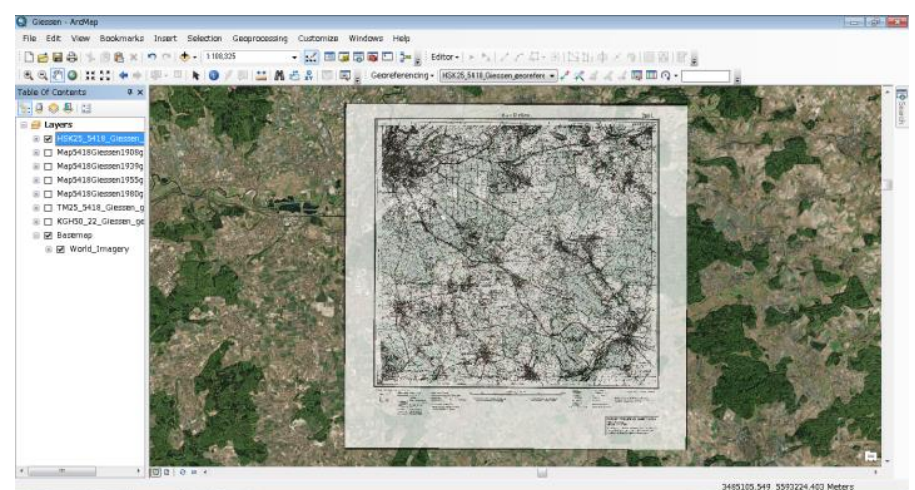

Figure 21. Map of Giessen: HSK25_5418 


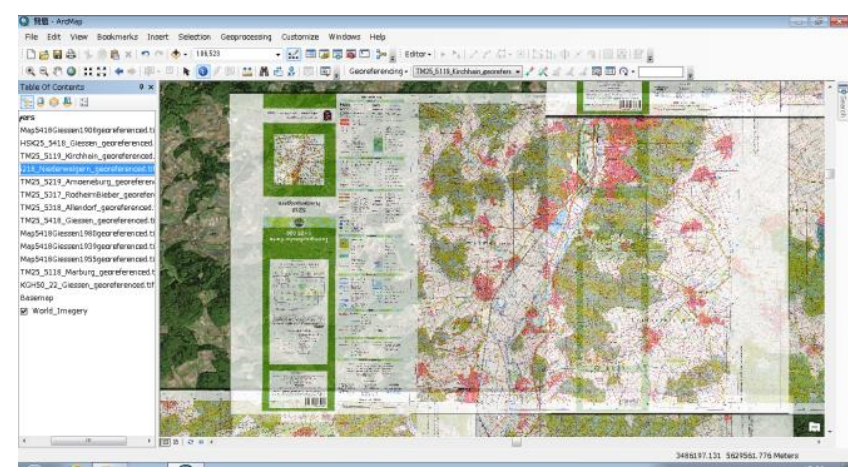

Figure 22. Map of Niederwalgern: TM25_5218

\section{CONCLUSIONS}

This paper aims to describe the procedure of development and future application of EI-EIS. The purpose of the EI-EIS is to evaluate functions of Eco-DRR. In order to analyse disaster data, collection of past disaster information, and disaster-prone area is effective.

First, a number of digital maps and analogue maps in Japan and Europe were collected. In total, 18,572 maps over 100 years were collected. The Japanese data includes Future-Pop Data Series (1,736 maps), JMC dataset 50m grid (elevation) (13,071 maps), Old Edition Maps: Topographic Map (325 maps), Digital Base Map at a scale of 2500 for reconstruction planning (808 maps), Detailed Digital Land Use Information for Metropolitan Area (10 m land use) (2,436 maps), and Digital Information by GSI (national large scale map) (71 maps). Old Edition Maps: Topographic Map were analogue maps, and were scanned and georeferenced. These geographical area covered 1) Tohoku area, 2) Five Lakes of Mikata area (Fukui), 3) Ooshima Island (Tokyo), 4) Hiroshima area (Hiroshima), 5) Okushiri Island (Hokkaido), and 6) Toyooka City area (Hyogo). The European data includes topographic map in Germany (8 maps), old topographic map in Germany (31 maps), ancient map in Germany (23 maps), topographic map in Austria (9 maps), old topographic map in Austria (17 maps), and ancient map in Austria (37 maps).

Second, focusing on Five Lakes of Mikata area in Fukui Prefecture of Japan and several areas of Austria and Germany as demonstration, these maps were integrated into the ArcGIS Online $^{\circledR}$ (ESRI). These data can be overlaid, and time-series data can be visualized by a time slider function of ArcGIS Online.

\section{ACKNOWLEDGEMENTS}

This research was supported by the Environment Research and Technology Development Fund (4-1505) of the Ministry of the Environment, Japan.

\section{REFERENCES}

Federal Office of Metrology and Surveying: BEV, 2016a. Historische Karten, from http://www.bev.gv.at/portal/page?_pageid=713,1572459\&_dad =portal\&_schema=PORTAL (17 April 2016)

Federal Office of Metrology and Surveying: BEV, 2016b. Österreichische Karte 1:50 000 - UTM from http://www.bev.gv.at/portal/page?_pageid=713,1570629\&_dad =portal\&_schema=PORTAL (17 April 2016)

Geospatial Information Authority of Japan, 2016. Old Edition Map: Topographic Map (Japan), from http://www.gsi.go.jp/MAP/HISTORY/koufu.html (17 April 2016)

Gupta, A. K., \& Nair, S. S., 2012. Ecosystem approach to disaster risk reduction. National Institute of Disaster Management, New Delhi, India, 202.

Hessische Verwaltung für Bodenmanagement und Geoinformation (HVBG), 2016a. Historische Topographische Karten, from https://hvbg.hessen.de/irj/HVBG_Internet?cid=2af09b55ff7731 3be11d8452eee3ab75 (17 April 2016)

Hessische Verwaltung für Bodenmanagement und Geoinformation (HVBG), 2016b. Topographic map (Germany) [Topographische Karten zeigen die Formen der Erdoberfläche], from

https://hvbg.hessen.de/irj/HVBG_Internet?cid=0298aaecf3a637 026a3d47a6684d1b2a (17 April 2016)

Japan Map Center Foundation, 2016a. Detailed Digital Land Use Information for Metropolitan Area (10 m land use) (Japan), from http://net.jmc.or.jp/searchDigiMap_10mTochiEx.asp (17 April 2016)

Japan Map Center Foundation, 2016b. Digital Base Map at a scale of 2500 for reconstruction planning (Japan), from https://net.jmc.or.jp/digital_data_gsiol_saigai2500.html (17 April 2016)

Japan Map Center Foundation, 2016c. Digital Information by GSI (national large scale map) (Japan), from http://net.jmc.or.jp/digital_data_gsiol_kokudokihon.html (17 April 2016)

Japan Map Center Foundation, 2016d. JMC dataset 50m grid (elevation),

from http://net.jmc.or.jp/digital_data_map_jmc50mdem.html April 2016)

Microbase Co. Ltd., 2016. Future-Pop Data Series, from http://microbase.co/futurepop (17 April 2016)

Renaud, F. G., Sudmeier-Rieux, K., \& Estrella, M., 2013. The Role of Ecosystems in Disaster Risk Reduction: United Nations University Press. 